\title{
ESTUDO ANALÍTICO DE ÁGUAS DE ABASTECIMENTO UTILIZANDO TRATAMENTO COM ADSORVENTE FARINHA DE BANANA VERDE
}

\author{
Ana Priscila de Souza 1; Ana Maria de Souza Araújo²; Francisco Carlos de \\ Medeiros Filho ${ }^{3}$; Denise Domingos da Silva ${ }^{4}$
}

${ }^{1}$ Curso de Licenciatura em Química, Universidade Federal de Campina Grande, Lab. Bioambi, Cuité, PB, Lab. Bioambi, Brasil.

${ }^{2}$ Curso de Licenciatura em Química, Universidade Federal de Campina Grande, Lab. Bioambi, Cuité, PB, Lab. Bioambi, Brasil.

${ }^{3}$ Curso de Ciências Naturais e Biotecnologia, Programa de Pós-graduação em Ciências Naturais e Biotecnologia, Universidade Federal de Campina Grande, Lab. Bioambi, Cuité-PB, Brasil

${ }^{4}$ Profa ${ }^{a}$ Unidade Acadêmica de Biologia e Química, Universidade Federal de Campina Grande, Lab. Bioambi, Cuité, PB, Brasil.

Email para correspondência: denise.domingos@professor.ufcg.edu.br

\section{Resumo}

\begin{abstract}
A água é um dos recursos naturais mais importantes, principalmente devido às propriedades químicas e físicas, além de ser essencial para a vida e manutenção dos seres vivos. O Brasil possui grande disponibilidade hídrica, no entanto, algumas regiões enfrentam problemas graves de escassez de água. Com a crescente contaminação da água por diversos poluentes surge a necessidade do desenvolvimento de novos métodos de tratamento que sejam baratos, eficientes, renováveis e não produzam resíduos poluentes que degradem o meio ambiente. Desse modo, o uso de adsorventes naturais tem se tornado uma alternativa para o tratamento de águas. Assim, o presente trabalho teve como objetivo fazer um estudo analítico das propriedades tais como $\mathrm{pH}$, condutividade elétrica, turbidez, sólidos totais, cloretos, alcalinidade e dureza total de águas de abastecimento do município de São Vicente do Seridó - PB e foi utilizado tratamento com adsorvente proveniente da farinha de banana verde. Após a realização do estudo constatou-se que tratamento promoveu significativa redução da dureza e da turbidez. Apresentou pequenas variações nos demais parâmetros com exceção do $\mathrm{pH}$, o qual apresentou um aumento no teor de acidez das amostras. Os demais parâmetros se mantiveram em conformidade com os padrões exigidos pela Portaria № 5/2017 do Ministério da Saúde.
\end{abstract}

Palavras-chave: análise de águas, farinha de banana verde, adsorção

\section{Abstract / resumen / résumé}




\begin{abstract}
Water is one of the most important natural resources, mainly due to its chemical and physical properties, in addition to being essential for the life and maintenance of living beings. Brazil has great water availability, however, some regions face serious problems of water scarcity. With the increasing contamination of water by various pollutants, there is a need to develop new treatment methods that are cheap, efficient, renewable and do not produce polluting residues that degrade the environment. Thus, the use of natural adsorbents has become an alternative for water treatment. Thus, the present work aimed to make an analytical study of properties such as $\mathrm{pH}$, electrical conductivity, turbidity, total solids, chlorides, alkalinity and total hardness, in the municipality of São Vicente do Seridó - PB and treatment with adsorbent from green banana flour was used. After conducting the study, it was found that treatment promoted a significant reduction in hardness and turbidity. It presented small variations in the other parameters with the exception of $\mathrm{pH}$, which showed an increase in the acidity content of the samples. The other parameters remained in accordance with the standards required by Ordinance No. 5/2017 of the Ministry of Health.
\end{abstract}

Keywords: water analysis, green banana flour, adsorption

\title{
1 Introdução
}

A água é vital na manutenção da vida no planeta, e possui grande importância para a indústria. No entanto, devido tendências globalistas atuais, como o aumento populacional, crescimento urbano, entre outros, há expectativas que em até 50 anos a escassez de água afetará, pelo menos, metade da população mundial.

Esta conjuntura se dá em razão da poluição de fontes hídricas e do mau uso desse recurso, do desmatamento, do aquecimento global e principalmente da falta de políticas públicas.

No Brasil, a crise hídrica atinge a maioria da população. "As primeiras práticas políticas criadas para diminuição da problemática foi a criação de açudes para a população da zona urbana seguido de escavações de poços e cisternas para a população rural (CAMPOS; MAGALHÃES, 2012).

Segundo Montenegro e Montenegro (2012), dentre as regiões submetidas à insuficiência de água, destacam-se as zonas semiáridas, por suas condições de escassez, sucessíveis as chuvas de distribuição irregular. Como resultado, as incertezas referentes à disponibilidade de água para os mais variados usos tendem a ser elevadas, dificultando o planejamento voltado ao uso responsável dos recursos hídricos devido principalmente às irregularidades do escoamento superficial e do armazenamento nos pequenos açudes, como é o caso do município de São Vicente do Seridó, localizado no Curimataú paraibano (SILVA et. al, 2015). 
O controle da qualidade da água de uma determinada região deve englobar uma verificação das principais práticas que venham a afetar na qualidade destas águas. Segundo Konig (2008), as principais fontes de poluição das águas são derivadas do alto grau de urbanização associado à falta de ações de saneamento básico.

Em São Vicente do Seridó - PB, a poluição e contaminação das águas é uma realidade que afetou a distribuição de água no município, que, por não ter havido uma preservação ambiental em seu entorno, o açude Felismina Queiroz, que abastecia a cidade, hoje não é mais considerado uma fonte de água potável e consequentemente não se utiliza para consumo humano (SILVA et. al, 2015).

Isto posto, a indústria busca meios de reverter essas situações, buscando recursos que minimizem os contaminantes presentes em águas para que estas sejam tratadas. Um dos métodos mais utilizados para o tratamento de águas é a adsorção.

A adsorção é um dos processos mais eficientes no tratamento de águas, sendo empregadas nas indústrias com o intuito de diminuir dos seus efluentes os níveis de compostos tóxicos ao meio ambiente (MOREIRA, 2008). Trata-se de um fenômeno físico-químico de grande utilidade, por possuir inúmeras aplicações e decorre quando um componente (adsorvato), seja em fase líquida ou gasosa, é transferido para a superfície de uma fase sólida (adsorvente). Essa técnica permite o tratamento especifico do adsorvato, ou seja, a matriz conhecida a partir de adsorventes, que podem ser sintéticos ou naturais.

O uso do adsorvente natural garante a capacidade de remoção de contaminantes, reuso da água, utilidade do subproduto, que geralmente é descartado pela falta de utilidade aparente.

Diante do exposto, pesquisas recentes apontam que a farinha de banana verde apresenta propriedades que atuam como adsorventes no tratamento de águas (BUSKE, 2012).

Assim sendo, o presente trabalho tem como objetivo fazer um estudo analítico das propriedades físico-químicas das águas de abastecimento do município de São Vicente do Seridó - PB, e propor um tratamento para estas águas, utilizando farinha de banana verde como adsorvente natural. A pesquisa 
trará contribuições relevantes à população de São Vicente do Seridó - PB, pois permitirá o conhecimento a respeito da qualidade das águas na região do Curimataú paraibano, bem como a utilização de um novo método de tratamento para estas águas.

\section{Metodologia}

\section{1 Área de estudo}

A área de estudo está localizada no município de São Vicente do Seridó PB, situado a 263 km da Capital do estado. Com uma população estimada em 10.775 habitantes, possui uma área de 276,46 km² (IBGE, 2019). O município se localiza na microrregião do Curimataú paraibano, semiárido brasileiro, que faz a área ser vulnerável às variações climáticas devido às chuvas irregulares, deficiência hídrica, o ciclo forte de estiagens e secas que atingem a região, em intervalos que podem durar poucos ou muitos anos.

Atualmente o sistema de abastecimento de água do município é feito através do açude Epitácio Pessoa, popularmente conhecido como Boqueirão.

O reservatório está localizado na região semiárida paraibana, a $165 \mathrm{~km}$ da capital do estado, na mesorregião da Borborema, especificamente na microrregião do Cariri Oriental paraibano, na Bacia Hidrográfica do Rio Paraíba (BRITO; VIANNA, 2008).

\subsection{Coleta das amostras}

As coletas das amostras de águas de abastecimento e de poços subterrâneos são de localidades diferentes. Cada coleta foi realizada em triplicata e as amostras de cada ponto identificadas e armazenadas em garrafas de politereftalato de etileno (PET) com capacidade de 2,0 L previamente higienizadas, preenchidas por completo e mantidas em refrigeração durante todo período das análises. $O$ quadro 1 apresenta as localidades de coleta das amostras. 
Quadro 1. Localização dos pontos de coleta do município de São Vicente do Seridó PB.

\begin{tabular}{|c|c|}
\hline Amostras & Localidades \\
\hline A & Rua Maria Alcira \\
\hline B & Rua Nova Brasília \\
\hline C & Rua Maria Tereza \\
\hline D & Rua Venâncio Joaquim dos Santos \\
\hline E & Rua Afonso Pereira de Souza \\
\hline
\end{tabular}

Fonte: Dados da pesquisa, 2020.

Figura 1: pontos de coleta das amostras A, B, C,D.

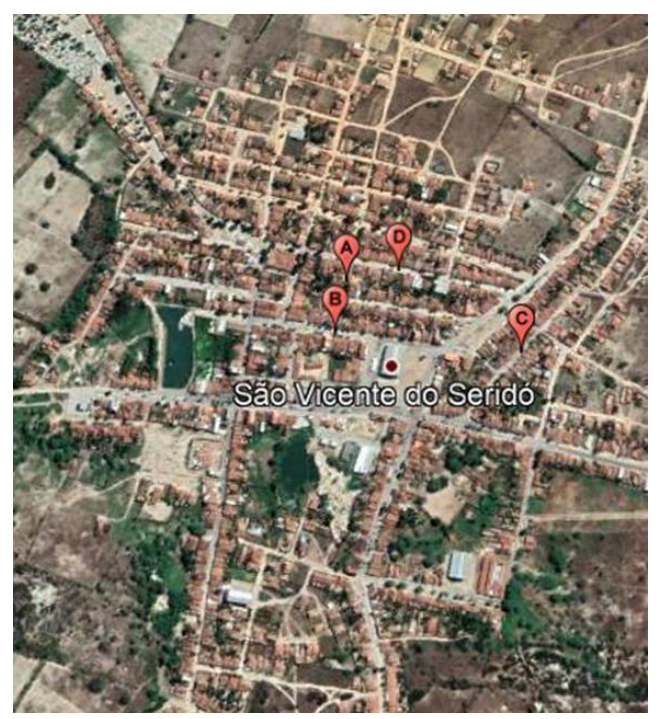

Figura 2: ponto de coleta da amostra E.

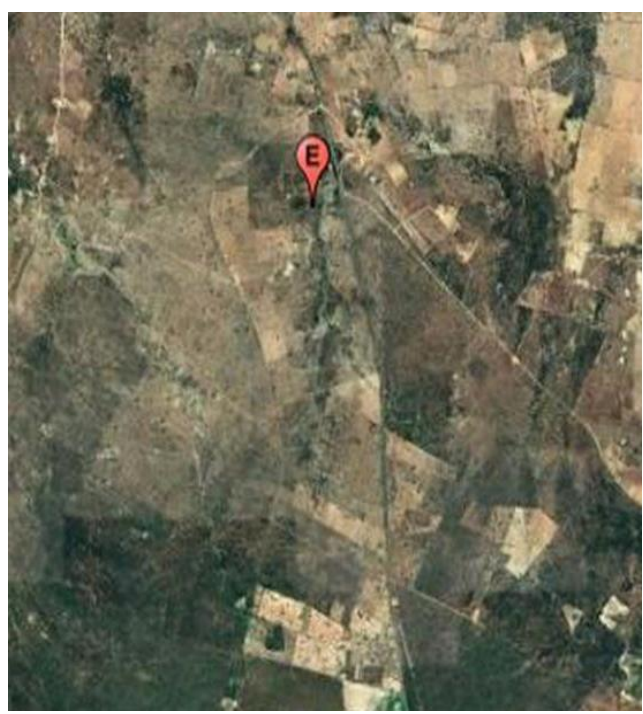

Fonte:https://www.google.com/maps/place/S\%C3\%A3o+Vicente+do+Serid\%C3\%B3,+Serid\%C 3\%B3++PB,+58158000/@6.9337215,36.4033799,1110m/data=!3m1!1e3!4m5!3m4!1s0x7aef0d da83e73e3:0xd0b9cbcf232dcaa2!8m2!3d-6.933743!4d-36.401191.

\subsection{Caracterização físico-química das amostras de águas}

As análises foram realizadas nos laboratórios de Química Analítica, Farmácia Escola e no laboratório de Química Ambiental e Biocombustíveis (Bioambi) do Centro de Educação e Saúde da Universidade Federal de Campina Grande e seguirão metodologias recomendadas pelo Standard Methods or the Examination of Water (APHA, 2006), pelo manual prático de análise de água da Fundação Nacional da Saúde (FUNASA, 2014) e pelo livro Águas e Águas métodos laboratoriais de análises físico químicas e microbiológica (MACÊDO, 2001). Todas as determinações foram realizadas em triplicata. 


\section{4 pH (Potencial Hidrogeniônico)}

$\mathrm{Na}$ determinação de $\mathrm{pH}$ das amostras foram realizadas em um peagâmetro pH 21 - Hanna, sendo o mesmo previamente calibrado com soluções tampão ácido de 4,00 \pm 0,01 e neutro de 7,00 $\pm 0,01$ (ALPHA, 2012).

\subsection{Condutividade elétrica}

A condutividade foi determinada utilizando um condutivímetro mCA150/Mca-150P sendo previamente calibrado com solução padrão de cloreto de potássio $(\mathrm{KCl}) 146,9 \mu \mathrm{S} / \mathrm{cm} \pm 0,5 \%$, com uma temperatura padronizada de $25^{\circ} \mathrm{C}$.

\subsection{Turbidez}

A turbidez foi determinada por um turbidímetro modelo TB1000, previamente calibrado com soluções padrões de 0,1 NTU, 0,8 NTU, 8 NTU, 80 NTU e 1000 NTU. Em seguida, o recipiente foi lavado três vezes com água destilada e posteriormente com a água da amostra. A leitura das amostras foi realizada em triplicata, acompanhadas com desvio padrão (ALPHA, 2012).

\subsection{Dureza total}

Para determinação da dureza foi utilizado o método clássico de Volumetria de Complexação utilizando o agente titulante EDTA (ácido etilenodiaminotetracético) com a concentração de 0,01 mol.L-1 e utilizando como indicador Negro de Eriocromo - T com pH 9,4. (APHA, 2012).

\subsection{Cloretos}

Na determinação de cloretos foi utilizado a Volumetria de Precipitação com Nitrato de Prata $\left(\mathrm{AgNO}_{3}\right)$ 0,1 mol.L-1 pelo método de Mohr. E como indicador o Cromato de Potássio $\left(\mathrm{K}_{2} \mathrm{CrO}_{4}\right)$ 0,1 mol.L-1. (APHA, 2012).

\subsection{Alcalinidade}

As medidas de alcalinidade foram realizadas pelo método de volumetria de neutralização com ácido sulfúrico $\left(\mathrm{H}_{2} \mathrm{SO}_{4}\right) \quad 0,02$ mol.L-1 agente titulante e solução indicadora alaranjado de metila $0,1 \mathrm{~mol}^{-L^{-1}}$. (APHA, 2012). 


\subsection{Sólidos dissolvidos totais (SDT)}

Os valores de sólidos dissolvidos totais (SDT) foram estimados a partir dos valores de condutividade elétrica (CE) indicados pela equação de Holanda e Amorim (apud Casali 2008).

\subsection{Adsorvente natural}

A farinha de banana verde, da marca Natural Life, é formulada a partir da polpa e da casca da fruta. A embalagem possui $150 \mathrm{~g}$ e para cada amostra foi pesada $3 \mathrm{~g}$ da farinha de banana verde para ser utilizada no tratamento. $\mathrm{O}$ adsorvente não sofreu nenhuma alteração física, tendo sido utilizado da forma original de embalagem.

\subsection{Adsorção química por cromatografia em coluna}

Após a determinação dos parâmetros físico-químicos das amostras de água foram realizados testes de adsorção nos quais as amostras foram tratadas por meio de cromatografia em coluna.

Alguns parâmetros analisados antes do tratamento, como dureza total e $\mathrm{pH}$ serão repetidos após o tratamento com o adsorvente proveniente da farinha de banana verde para comparação dos resultados.

Para o tratamento com a cromatografia em coluna, foi utilizada a bureta de $25 \mathrm{ml}$, onde uma pequena porção de algodão foi umedecida e colocada na parte inferior da bureta, próximo a torneira. Em seguida a coluna foi preenchida com $3 \mathrm{~g}$ do adsorvente (fase estacionária), que foi previamente lavado com água destilada até que a água estivesse límpida. Após verificada a limpidez da água destilada, foram percolados $40 \mathrm{ml}$ das amostras de águas de abastecimento com vazão de 22 gotas/min.

\subsection{Adsorção química por filtração}

Para o tratamento das amostras por meio de filtração foram utilizados $3,0 \mathrm{~g}$ do adsorvente para cada amostra. Após ser pesado em uma balança analítica, o adsorvente foi adicionado em um becker, o qual, em seguida, foi acrescido de água destilada e levado ao agitador magnético. Após 10 minutos de agitação, a amostra foi filtrada em papel filtro qualitativo com vazão de 42 gotas/min. 
Após a lavagem do adsorvente com água destilada, foram adicionados ao filtro $100 \mathrm{ml}$ das amostras de água de abastecimento e em seguida foram analisados os parâmetros das águas tratadas com o adsorvente de farinha de banana verde.

\section{Resultados}

\subsection{Caracterização físico-química das amostras de água}

As tabelas 1 e 2 apresentaram valores médios com desvio padrão dos parâmetros físico-químicos, dureza total, $\mathrm{pH}$, condutividade elétrica, acidez, alcalinidade, cloretos, turbidez e sólidos totais das amostras de águas analisadas do município de São Vicente do Seridó - PB.

Em relação à dureza total, observa-se que todas as amostras apresentaram valores que estão em conformidade com o que a Portaria oㅡ 5/2017 do Ministério da Saúde (MS), permite. De acordo com a Portaria, a concentração máxima de carbonato de cálcio $\left(\mathrm{CaCO}_{3}\right)$ permitida para águas é de $500 \mathrm{mg} / \mathrm{L}$. Dentre as amostras analisadas, observa-se que a que possui maior concentração de $\mathrm{CaCO}_{3}$ é a amostra $\mathrm{B}$ (410), no entanto esse valor encontra-se dentro do permitido pelo MS.

Para $\circ \mathrm{pH}$, os valores estão de acordo com o MS. Todas as amostras apresentaram pH entre 6,0 e 8,5 e estão em conformidade com a Portaria no $5 / 2017$ do MS, que recomenda que o $\mathrm{pH}$ água seja mantido na faixa de 6,0 a 9,5 no sistema de distribuição.

No que diz respeito a condutividade, a Portaria no 5/2017 não especifica valores permitidos para condutividade ideal. De acordo com a Tabela 1, observa-se que os valores de condutividade das amostras variam de 604,26 a 682,4 .

As concentrações de cloretos apresentaram baixos valores, variando de 0,164 a 0,496 . Geralmente os cloretos estão presentes em águas brutas e tratadas em concentrações que podem variar de pequenos traços até centenas de $\mathrm{mg} / \mathrm{L}$. Concentrações altas de cloretos podem restringir o uso da água em razão do sabor que eles conferem e pelo efeito laxativo que eles podem provocar. A Portaria no 5/2017 do MS estabelece o teor de $250 \mathrm{mg} / \mathrm{L}$ como o valor máximo permitido para água potável (FUNASA, 2014). 
Tabela 1. Análises físico-químicas das águas de São Vicente do Seridó-PB.

\begin{tabular}{|c|c|c|c|c|}
\hline Amostras & $\begin{array}{c}\text { Dureza } \\
\left(\mathrm{mg} / \mathrm{L} \mathrm{de} \mathrm{CaCO}_{3}\right)\end{array}$ & $\mathrm{pH}$ & $\begin{array}{l}\text { Condutividade } \\
\mathrm{mS} / \mathrm{cm} \text { a } 25^{\circ} \mathrm{C}\end{array}$ & $\begin{array}{l}\text { Cloretos } \\
\text { (mg/L) }\end{array}$ \\
\hline A & $360 \pm 0,31$ & $6,0 \pm 0,031$ & $680,0 \pm 0,10$ & $0,496 \pm 0,21$ \\
\hline B & $410 \pm 0,12$ & $6,53 \pm 0,025$ & $682,4 \pm 0,50$ & $0,426 \pm 0,26$ \\
\hline C & $370 \pm 0,25$ & $6,64 \pm 0,020$ & $678,0 \pm 0,40$ & $0,147 \pm 0,06$ \\
\hline D & $340 \pm 0,06$ & $6,77 \pm 0,015$ & $679,0 \pm 0,25$ & $0,164 \pm 0,06$ \\
\hline E & $340, \pm 0,10$ & $6,76 \pm 0,006$ & $604,26 \pm 0,40$ & $0,375 \pm 0,06$ \\
\hline $\begin{array}{c}\text { Máximo } \\
\text { permitido pelo } \\
\text { MS }\end{array}$ & 500 & $6,5 \leq \mathrm{pH} \leq 9,5$ & $\begin{array}{c}\text { Não } \\
\text { especificado }\end{array}$ & 250 \\
\hline
\end{tabular}

Dentre as amostras de alcalinidade, apresentaram-se de 72 a $120 \mathrm{mg} / \mathrm{L}$, onde as amostras A, B, D e E apresentam valores aproximados, e a amostra C (72 mg/L) apresentando mais baixa alcalinidade em relação às demais. $A$ Portaria no $5 / 2017$, não especifica, no entanto, valor adequado de alcalinidade em águas, visto que esta não representa risco potencial à saúde pública.

Segundo a FUNASA (2014), a turbidez da água se dá em consequência da presença de materiais sólidos em suspensão, que reduzem a sua transparência. Verifica-se que há grande diferença de turbidez da amostra $D$ $(10,49 N T U)$, que apresenta um valor muito elevado em relação ao que recomenda o MS (5,0 NTU). As demais amostras variam entre 0,15 e 0,34 NTU, estando dentro do padrão exigido pela Portaria.

Constata-se que as amostras apresentaram alta concentração de sólidos totais. Os sólidos totais dissolvidos nas águas representam toda a matéria que permanece como resíduo após evaporação, secagem ou calcinação da amostra a uma temperatura pré-estabelecida e durante um tempo fixado.

Na tabela 2 observa-se os valores de alcalinidade, turbidez e sólidos totais dissolvidos. 
Tabela 2. Análises físico-químicas das águas de São Vicente do Seridó-PB.

\begin{tabular}{c|c|c|c|}
\hline Amostras & $\begin{array}{c}\text { Alcalinidade } \\
(\mathbf{m g} / \mathbf{L})\end{array}$ & Turbidez $(\mathbf{N T U})$ & STD $(\boldsymbol{\mu S} . \mathbf{c m}-\mathbf{1})$ \\
\hline A & $106 \pm 0,10$ & $0,52 \pm 0,01$ & $462,468 \pm 0,04$ \\
B & $100 \pm 0,20$ & $0,45 \pm 0,02$ & $464,032 \pm 0,10$ \\
C & $72 \pm 0,05$ & $0,15 \pm 0,01$ & $461,312 \pm 0,01$ \\
D & $106 \pm 0,06$ & $10,49 \pm 0,15$ & $461,720 \pm 0,50$ \\
E & $120 \pm 0,15$ & $0,34 \pm 0,01$ & $410,897 \pm 0,30$ \\
\hline $\begin{array}{c}\text { Máximo permitido } \\
\text { pelo MS }\end{array}$ & Não especificado & $\mathbf{5 , 0}$ & Não especificado \\
\hline
\end{tabular}

Fonte: Dados da pesquisa, 2020.

\subsection{Análise físico-química após a utilização da adsorvente farinha de banana verde}

A farinha de banana verde foi testada como adsorvente por meio de cromatografia em coluna e filtração para avaliar a eficiência da adsorção de amostras de águas de abastecimento do município de São Vicente do SeridóPB. Observou-se que, na cromatografia, o adsorvente oxidou rapidamente e apresentou forte odor, sendo desse modo não promissor para o tratamento das amostras.

No processo de filtração o adsorvente (farinha de banana verde) obteve melhor resultado, se mostrando eficiente no tratamento das amostras.

A Tabela 3 apresenta os valores de dureza total, $\mathrm{pH}$ e cloretos antes e após adsorção da farinha de banana verde.

De acordo com a tabela, observa-se que houve uma considerável redução da dureza nas amostras após o tratamento com o adsorvente. A amostra $\mathrm{B}$, que apresentava maior concentração de $\mathrm{CaCO}_{3}$ (410 mg.L-1), teve uma diminuição significativa, atingindo $125 \mathrm{mg} \cdot \mathrm{L}-1$ de $\mathrm{CaCO}_{3}$. As demais amostras, A, C, D, e E que já apresentavam baixa dureza tiveram esses valores ainda mais diminuídos, apresentando concentrações de 100, 100, 110 e 100 mg.L-1 $\mathrm{CaCO}_{3}$, respectivamente. Todas se mantiveram de acordo com a portaria do $n^{0} 5 / 2017$. 
Tabela 3. Valores de dureza, $\mathrm{pH}$, cloretos antes e após o tratamento com o adsorvente (farinha de banana verde).

\begin{tabular}{|c|c|c|c|c|c|c|}
\hline \multirow{2}{*}{$\begin{array}{l}\text { FASES DAS } \\
\text { AMOSTRAS }\end{array}$} & \multirow{2}{*}{$\begin{array}{l}\text { PARÂMETRO } \\
\text { ANALISADO }\end{array}$} & \multicolumn{5}{|c|}{ AMOSTRAS } \\
\hline & & A & B & C & D & $E$ \\
\hline \multirow{3}{*}{$\begin{array}{c}\text { ANTES DO } \\
\text { TRATAMENTO }\end{array}$} & $\begin{array}{c}\text { Dureza } \\
\text { (mg/L de } \\
\mathrm{CaCO}_{3} \text { ) }\end{array}$ & $360 \pm 0,31$ & $410 \pm 0,12$ & $370 \pm 0,12$ & $340 \pm 0.06$ & $340, \pm 0,1$ \\
\hline & $\mathrm{pH}$ & $6,0 \pm 0,031$ & $6,0 \pm 0,031$ & $6,0 \pm 0,031$ & $6,77 \pm 0,015$ & $6,77 \pm 0,015$ \\
\hline & $\begin{array}{c}\text { Cloretos } \\
(\mathrm{mg} / \mathrm{L})\end{array}$ & $0,496 \pm 0,2$ & $0,496 \pm 0,21$ & $0,147 \pm 0,06$ & $0,147 \pm 0,06$ & $0,147 \pm 0,06$ \\
\hline \multirow{3}{*}{$\begin{array}{c}\text { APÓSO } \\
\text { TRATAMENTO }\end{array}$} & $\begin{array}{c}\text { Dureza } \\
\text { (mg/L de } \\
\mathrm{CaCO}_{3} \text { ) }\end{array}$ & $100 \pm 0,10$ & $125 \pm 0,5$ & $100 \pm 32$ & $110 \pm 0,05$ & $100 \pm 0,6$ \\
\hline & $\mathrm{pH}$ & $5,8 \pm 0,12$ & $5,9 \pm 0,5$ & $6,1 \pm 0,32$ & $6,5 \pm 0,03$ & $6,3 \pm 0,01$ \\
\hline & $\begin{array}{c}\text { Cloretos } \\
\text { (mg/L) }\end{array}$ & $0,490 \pm 0,1$ & $0,410 \pm 0,2$ & $0,140 \pm 0,3$ & $0,150 \pm 0,5$ & $0,360 \pm 0,1$ \\
\hline
\end{tabular}

Fonte: Dados da pesquisa, 2020.

Em relação ao $\mathrm{pH}$, observa-se uma diminuição, em alguns casos, como nas amostras A $(5,8)$ e B $(5,9)$, permanecendo com caráter ácido, porém, abaixo do valor permitido pelo MS $(6,0)$. Este fato pode estar relacionado com a utilização do adsorvente farinha de banana verde, que, quando se apresenta com casca, favorece um aumento na acidez.

A tabela 4 apresenta os valores de alcalinidade, turbidez e condutividade elétrica após o tratamento com o adsorvente.

Observa-se que em relação à alcalinidade não houve alterações significativas após o tratamento com o adsorvente, havendo apenas uma pequena diminuição do valor das amostras.

Em relação à turbidez, as amostras $A, B, C, e E$, que antes do tratamento já apresentavam baixos valores, se mantiveram em valores baixos de turbidez. Já amostra $D$, que antes do tratamento apresentou um valor muito acima do permitido (10,49 NTU) e após o tratamento apontou significativa diminuição em sua turbidez $(0,80)$. Dessa forma, verifica-se que o adsorvente apresentou grande eficiência no tratamento desta amostra no que se refere à 
turbidez, pois após o tratamento permaneceu em conformidade com a Portaria do MS.

Tabela 4. Valores de alcalinidade, turbidez e condutividade elétrica antes e após o tratamento com o adsorvente (farinha de banana verde).

\begin{tabular}{|c|c|c|c|c|c|c|}
\hline \multirow{2}{*}{$\begin{array}{l}\text { FASES DAS } \\
\text { AMOSTRAS }\end{array}$} & \multirow{2}{*}{$\begin{array}{l}\text { PARÂMETRO } \\
\text { ANALISADO }\end{array}$} & \multicolumn{5}{|c|}{ AMOSTRAS } \\
\hline & & $A$ & $B$ & $\mathrm{C}$ & $\mathrm{D}$ & $E$ \\
\hline \multirow{3}{*}{$\begin{array}{l}\text { ANTES DO } \\
\text { TRATAMENTO }\end{array}$} & $\begin{array}{c}\text { Alcalinidade } \\
(\mathrm{mg} / \mathrm{L})\end{array}$ & $106 \pm 0,10$ & $100 \pm 0,20$ & $72 \pm 0,05$ & $106 \pm 0,1$ & $120 \pm 0,15$ \\
\hline & Turbidez (NTU) & $0,52 \pm 0,01$ & $0,45 \pm 0,02$ & $0,15 \pm 0,01$ & $10,49 \pm 0,1$ & $0,34 \pm 0,01$ \\
\hline & $\begin{array}{c}\text { Condutividade } \\
(\mathrm{mS} / \mathrm{cm})\end{array}$ & $680,0 \pm 0,10$ & $680,0 \pm 0,10$ & $678,0 \pm 0,4$ & $679,0 \pm 0,2$ & $604,26 \pm 0,4$ \\
\hline \multirow{3}{*}{$\begin{array}{c}\text { APÓSO } \\
\text { TRATAMENTO }\end{array}$} & $\begin{array}{c}\text { Alcalinidade } \\
(\mathrm{mg} / \mathrm{L})\end{array}$ & $104 \pm 0,10$ & $101 \pm 0,5$ & $73 \pm 0,32$ & $106 \pm 0,05$ & $118 \pm 0,6$ \\
\hline & Turbidez (NTU) & $0,50 \pm 0,01$ & $0,46 \pm 0,05$ & $0,16 \pm 0,03$ & $0,80 \pm 0,03$ & $0,32 \pm 0,01$ \\
\hline & $\begin{array}{c}\text { Condutividade } \\
(\mathrm{mS} / \mathrm{cm})\end{array}$ & $678 \pm 010$ & $681 \pm 0,2$ & $675 \pm 0,3$ & $675 \pm 0,5$ & $600 \pm 0,1$ \\
\hline
\end{tabular}

Fonte: Dados da pesquisa, 2020.

\section{Conclusão}

O desenvolvimento deste estudo possibilitou analisar os parâmetros físico-químicos das águas do município de São Vicente do Seridó-PB e verificar a eficiência da farinha de banana verde como adsorvente para tratamento dessas águas.

O processo de filtração se mostrou mais eficaz no tratamento com o adsorvente que a cromatografia em coluna, visto que nesta última, o adsorvente apresentou características diferentes das suas propriedades originais. Desse modo, foi possível constatar que o adsorvente, através do processo de filtração, foi eficiente na redução da dureza total, porém não foi eficaz em relação ao $\mathrm{pH}$, onde houve uma diminuição no fator de acidez, deixando algumas amostras abaixo do padrão exigido pela Portaria 5/2017 do Ministério da Saúde.

Para os parâmetros de cloretos, alcalinidade e condutividade elétrica, observou-se pequenas variações após o tratamento. No que se refere a 
turbidez, o adsorvente demonstrou ser eficaz, visto que uma amostra que estava muito acima do valor permitido pelo Portaria 5/2017 do Ministério da Saúde teve sua turbidez reduzida a um valor muito baixo, que deixou a água dentro dos padrões do MS.

Sendo assim, a realização desta pesquisa demonstrou ser relevante por apresentar um adsorvente natural e de baixo custo, para tratamento de águas de abastecimento. $O$ estudo possibilitou também averiguar parâmetros físicosquímicos das águas que abastecem a população de São Vicente do Seridó-PB, concedendo à comunidade o conhecimento da qualidade da água consumida no município.

\section{Referências}

BRITO. F. B.; VIANA. P. C. G. Açude do Boqueirão, dez anos de desacertos (1998/2008), da crise de abastecimento ao afogamento do conflito. II Seminário Luso-Brasileiro Agricultura Familiar e Desertificação. João Pessoa PB, 2008.

BUSKE, J. L.; JOÃO, J. J. Biomassa residual: Utilização da casca da banana como adsorvente de metais pesados em efluentes líquidos industriais. In: JORNADA UNISUL DE INICIAÇÃO CIENTÍFICA, 2012, Tubarão. Anais eletrônicos... Santa Catarina: UNISUL, 2012. Disponível em:< http://www.rexlab.unisul.br/junic/2012/arquivo_sistema/resumo_expandido_201 2_21_08_17_5033ffe331925.pdf>. Acesso em: 28 de outubro de 2019.

CAMPOS, J. N. MAGALHÃES, A.R. A evolução das políticas públicas no Nordeste. A questão da água no Nordeste. Brasília: CGEE, 261-87, 2012.

Fundação Nacional de Saúde. Manual prático de análise de água. Brasília: FUNASA; 2013.

Instituto Brasileiro de Geografia e Estatística - IBGE. Semiárido Brasileiro, o que é: Publicação anual do Instituto Brasileiro de Geografia e Estatística. Disponível em: <https://www.ibge.gov.br/geociencias/cartas-e-mapas/mapas- 
regionais/15974-semiarido-brasileiro.html $?=\& \mathrm{t}=0$-que-e $>$. Acesso em: 03 de setembro de 2019.

KONIG, A. Usos da água In: FURTADO, D. A; KONIG, A. Gestão integrada de recursos hídricos. Campina Grande, PB.1ed. Agenda, 2008. cap.2.p.46.

MONTENEGRO, A. A, A; MONTENEGRO, S.M.G.L. Olhares sobre as políticas públicas de recursos hídricos para o semiárido. In: GHEYl. H, R. et al. (Ed.).

Recursos hídricos em regiões semiáridas: Estudos e aplicações. Campina Grande, PB: Instituto Nacional do Semiárido, Cruz das Almas, BA: UFRB, 2012. cap.1.

MOREIRA, S. de A. Adsorção de íons metálicos de efluente aquoso usando bagaço do pedúnculo de caju: estudo de batelada e coluna de leito fixo. 2008. 133 f. Dissertação (Mestrado em Saneamento Ambiental) Pós-graduação em Engenharia Civil da Universidade Federal do Ceará, Fortaleza, 2008. Disponível em: <http://www. teses.ufc.br/tde_busca/arquivo.php?codArquivo=1383>. Acesso em 14 de março de 2019.

SILVA, R. A.; SILVA FILHO, E. D.; JUNIOR, J. N.; BRAZ, A. S.; GONZAGA, F. A. S. Caracterização físico-química das águas de poços tubulares localizados nas cidades de Cuité e Areial no semiárido paraibano. In: 5o Simpósio de Segurança Alimentar - Alimentação e Saúde, 2015, Bento Gonçalves - RS. Anais. Bento Gonçalves: 2015.

\section{Agradecimentos}

Aos Laboratórios de Biocombustíveis e Química Ambiental (BIOAMBI), e a Farmácia Escola do Centro de Educação e Saúde ( UFCG) pela realização da pesquisa. 